\title{
Ultraviolet detection from energetically deposited titania films
}

Field, Matthew; Murdoch, Billy; McCulloch, Dougal; Partridge, James

https://researchrepository.rmit.edu.au/esploro/outputs/9921859413001341/filesAndLinks?institution=61RMIT_INST\&index=null

Field, M., Murdoch, B., McCulloch, D., \& Partridge, J. (2014). Ultraviolet detection from energetically deposited titania films. Applied Physics Letters, 104(13), 1-4. https://doi.org/10.1063/1.4870069

Document Version: Published Version

Published Version: https://doi.org/10.1063/1.4870069

Repository homepage: https://researchrepository.rmit.edu.au

(c) 2014 AIP Publishing LLC.

Downloaded On 2023/04/27 00:16:48 +1000 
Thank you for downloading this document from the RMIT Research Repository.

The RMIT Research Repository is an open access database showcasing the research outputs of RMIT University researchers.

RMIT Research Repository: http://researchbank.rmit.edu.au/

\section{Citation:}

Field, M, Murdoch, B, McCulloch, D and Partridge, J 2014, 'Ultraviolet detection from energetically deposited titania films', Applied Physics Letters, vol. 104, no. 13, pp. 1-4.

See this record in the RMIT Research Repository at:

http://researchbank.rmit.edu.au/view/rmit:24501

Version: Published Version

Copyright Statement: (C) 2014 AIP Publishing LLC.

Link to Published Version:

http://dx.doi.org/10.1063/1.4870069 


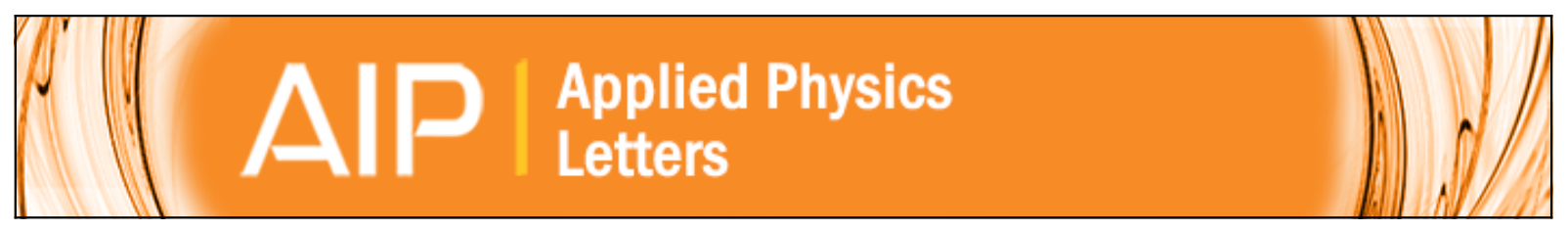

\title{
Ultraviolet detection from energetically deposited titania films
}

\author{
M. R. Field, B. J. Murdoch, D. G. McCulloch, and J. G. Partridge
}

Citation: Applied Physics Letters 104, 131905 (2014); doi: 10.1063/1.4870069

View online: http://dx.doi.org/10.1063/1.4870069

View Table of Contents: http://scitation.aip.org/content/aip/journal/apl/104/13?ver=pdfcov

Published by the AIP Publishing

\section{Articles you may be interested in}

Structural, morphological, FTIR and photoluminescence properties of gallium oxide thin films

J. Vac. Sci. Technol. B 32, 03D119 (2014); 10.1116/1.4868523

Resistive switching properties of amorphous Pr0.7Ca0.3MnO3 films grown on indium tin oxide/glass substrate using pulsed laser deposition method

Appl. Phys. Lett. 100, 212111 (2012); 10.1063/1.4722797

Synthesis, characterization, and photoactivity of In Ta O 4 and In $0.9 \mathrm{Ni} 0.1 \mathrm{Ta} O 4$ thin films prepared by electron evaporation

J. Vac. Sci. Technol. A 28, 127 (2010); 10.1116/1.3273597

Structural and electrical properties of metal contacts on $\mathrm{n}$-type $\mathrm{ZnO}$ thin film deposited by vacuum coating technique

J. Vac. Sci. Technol. B 27, 2124 (2009); 10.1116/1.3196786

Synthesis and characterization of $\mathrm{ZnO}$ thin film grown by electron beam evaporation

J. Appl. Phys. 99, 123105 (2006); 10.1063/1.2204333

\section{A|P| $\left.\right|_{\text {Applied Physics }} ^{\text {Journal of }}$}

Journal of Applied Physics is pleased to announce André Anders as its new Editor-in-Chief 


\title{
Ultraviolet detection from energetically deposited titania films
}

\author{
M. R. Field, B. J. Murdoch, ${ }^{\text {a) }}$ D. G. McCulloch, and J. G. Partridge \\ School of Applied Sciences, RMIT University, GPO Box 2476 V, Melbourne, VIC 3001, Australia
}

(Received 24 October 2013; accepted 20 March 2014; published online 2 April 2014)

\begin{abstract}
Thin films of unintentionally doped n-type titania have been energetically deposited from a filtered cathodic vacuum arc. All films were dense, smooth, and transparent with crystallinity depending on the deposition/annealing temperature. At a growth temperature of $600^{\circ} \mathrm{C}$, the preferred phase could be changed from rutile to anatase by increasing the oxygen process pressure thereby reducing dynamic annealing. $\mathrm{Pt} / \mathrm{TiO}_{\mathrm{x}} / \mathrm{Pt}$ ultraviolet detectors exhibiting rectifying current-voltage characteristics and ultraviolet-visible rejection ratios exceeding $10^{4}: 1$ were formed on selected films. (C) 2014 AIP Publishing LLC. [http://dx.doi.org/10.1063/1.4870069]
\end{abstract}

Titanium oxide (or titania) is a polymorphous, wide bandgap semiconducting material with electrical and optical properties that vary with its microstructure. ${ }^{1}$ The lower temperature anatase structure has an indirect optical bandgap of $\sim 3.2 \mathrm{eV},{ }^{2}$ whilst rutile titania has a direct optical bandgap of $\sim 3.0 \mathrm{eV}$. Anatase and rutile titania both exhibit high refractive index, good chemical stability, biocompatibility, high transmission in the visible region, and electrical conduction that can be readily tuned through doping and/or native defects. ${ }^{3}$ Existing applications include bio-coatings, ${ }^{4}$ biosensors, ${ }^{5}$ ultraviolet (UV) light detectors, ${ }^{6}$ solar cell layers, ${ }^{7}$ and transparent electronic devices. ${ }^{8}$ Thin films of titania are normally grown using low-energy physical vapour or chemical vapour deposition techniques. ${ }^{9-11}$ Energetic physical vapour deposition can produce high quality thin films over large areas and provides a means to access a greater variety of microstructures at lower growth temperatures. ${ }^{12}$

In this Letter, titania coatings were energetically deposited (up to $\sim 20 \mathrm{eV}$ ) using a filtered cathodic vacuum arc (FCVA). ${ }^{13}$ This method is capable of producing dense, well adhered metal oxide coatings over large areas with optical and electrical properties suitable for device applications. ${ }^{14-17}$ The microstructures, optical, and electrical properties of films dynamically annealed during growth were compared with those deposited at room temperature (RT) and subsequently annealed. In addition to studying the crystallography and local bonding, the titania films were evaluated as active layers in UV light detectors.

All the titania films were deposited at floating potential onto quartz and sapphire substrates using a Nanofilm FCVA system ${ }^{18}$ equipped with a $68 \mathrm{~mm}$ diameter $99.99 \%$ purity $\mathrm{Ti}$ cathode. The arc current was $115 \mathrm{~A}$ and other operating conditions were as shown in Table I. The sheet resistances of the $\mathrm{TiO}_{\mathrm{x}}$ films (also shown in Table I) were measured at room temperature using an Ecopia HMS-3000 system and lithographically defined Van der Pauw Ti/Au Ohmic contacts. Atomic force microscopy, performed using tapping mode, revealed uniform morphologies with surface roughness less than $1 \%$ of the film thickness. The composition of the films was analysed using X-ray photoelectron spectroscopy and

\footnotetext{
${ }^{\text {a) }}$ Author to whom correspondence should be addressed. Electronic mail: billy.murdoch@rmit.edu.au
}

found to be within $1 \%$ of stoichiometric $\mathrm{TiO}_{2}$. As shown in Fig. 1, X-ray diffraction (XRD) (obtained using a Bruker D8 Discover GADDS micro-diffractometer with monochromatic $\mathrm{Cu} \mathrm{K} \alpha$ source) revealed an amorphous microstructure in the film prepared at room temperature. Powder standards (Deguss P25 with anatase:rutile:amorphous ratio of 78:14:8 as-received and largely rutile after annealing at $800^{\circ} \mathrm{C}$ ) show clear peaks associated with the anatase and rutile phases.

The local bonding in the RT film was investigated using $\mathrm{X}$-ray absorption spectroscopy (using the soft X-ray beamline at the Australian synchrotron). The X-ray absorption near edge structure (XANES) of the $\mathrm{Ti}_{2}$ and $\mathrm{L}_{3}$ edges (collected using the Auger electron yield) is shown in Fig. 2. The figure also shows the corresponding edges from the P25 and An-P25 powder standards and from a Ti foil (Ti). Peaks $\mathrm{a}$ and $\mathrm{b}$ arise from interactions between the newly formed core-hole and poorly screened 3 d electrons. ${ }^{19}$ The $\mathrm{L}_{2}$ and $\mathrm{L}_{3}$ edges each consist of a doublet caused by crystal field splitting of the $L$ energy bands into $e_{g}$ and $t_{2 g}$ sub bands, seen clearly in the spectrum from the Ti foil. Changes in the long range order of the sample can cause further splitting of each $e_{\mathrm{g}}$ peak into $\mathrm{d}_{1}$ and $\mathrm{e}_{1}$ peaks. ${ }^{20}$ This splitting is evident in the $\mathrm{L}_{3}$ peak from the P25 and An-P25 standards but, due to lifetime broadening, is not clear in the $\mathrm{L}_{2}$ peak. The $\mathrm{L}_{3}-\mathrm{e}_{\mathrm{g}}$ peak is sensitive to the bonding environment and is frequently used to identify the phase of the material. Changes in the phase (from a mixed phase to rutile) after annealing the P25 powder standard become clear with the increase in intensity of the $e_{1}$ peak relative to the $d_{1}$ peak. The XANES from the RT film is similar to that from the largely anatase (as-received) $\mathrm{P} 25$, indicating that anatase bonding is prevalent in this film. However, the broader $\mathrm{e}_{\mathrm{g}}$ peaks from RT are consistent with its highly disordered microstructure.

A typical UV-visible transmission plot with accompanying Tauc plot $^{21}$ is shown in Fig. 3 with the extracted optical bandgaps from all films shown in Table I. The low resistivity and optical bandgap exhibited by the RT film are consistent with a disordered anatase material. The defects most likely to cause the low resistivity of this film are those related to oxygen deficiency. Pt contacts, consisting of 20 inter-digital strips each of thickness $10 \mathrm{~nm}$, length $280 \mu \mathrm{m}$, and width $6 \mu \mathrm{m}$, were lithographically patterned on all films and their current-voltage $(I-V)$ characteristics were measured in light 
TABLE I. Film synthesis conditions and key properties of the $\mathrm{TiO}_{\mathrm{x}}$ coatings prepared using FCVA.

\begin{tabular}{lccccccc}
\hline \hline Film ID & $\begin{array}{c}\text { Deposition } \\
\text { temp. }\end{array}$ & $\begin{array}{c}\text { Oxygen pressure } \\
(\mathrm{mT} \text { Torr) }\end{array}$ & $\begin{array}{c}\text { Annealing } \\
\text { temp. }\end{array}$ & $\begin{array}{c}\text { Optical } \\
\text { bandgap (eV) }\end{array}$ & $\begin{array}{c}\text { Sheet resistance } \\
(\mathrm{M} \Omega / \square)\end{array}$ & $\begin{array}{c}\text { Dark:UV current } \\
\text { ratio (at 1 V) }\end{array}$ & Structure \\
\hline RT & Room temp. & 1.5 & $\ldots$ & 3.3 & 2.4 & $1: 1$ & Amorphous anatase \\
An-650 & Room temp. & 1.5 & $650^{\circ} \mathrm{C}$ & 3.2 & 31 & $1: 20$ & Polycryst. rutile and anatase \\
An-750 & Room temp. & 1.5 & $750^{\circ} \mathrm{C}$ & 3.2 & 480 & $1: 1000$ & Polycryst. rutile \\
600 & $600{ }^{\circ} \mathrm{C}$ & 1.5 & $\ldots$ & 3.1 & 22 & $1: 2$ & Polycryst. rutile \\
$600-\mathrm{HO}$ & $600{ }^{\circ} \mathrm{C}$ & 3.0 & $\ldots$ & 3.2 & $2.9 \times 10^{6}$ & $1: 400$ & Polycryst. anatase \\
\hline \hline
\end{tabular}

and dark conditions. The active area of each device was assumed to be $500 \times 500 \mu \mathrm{m}^{2}$. Illumination through the substrate was achieved using light emitting diodes (calibrated to provide equal optical power density and with $<20 \mathrm{~nm}$ FWHM) with different centre wavelengths $\left(\lambda_{\mathrm{c}}\right)$ mounted beneath the detectors on a purpose made probe station. The RT film exhibited Ohmic characteristics and little sensitivity to light.

Samples of the RT film were annealed in vacuum for $1 \mathrm{~h}$ at temperatures straddling the commonly accepted anatase-rutile bulk transition temperature. ${ }^{22}$ The XRD from the film annealed at $650{ }^{\circ} \mathrm{C}(\mathrm{An}-650)$ was consistent with a mixed microstructure with peaks attributable to both anatase and rutile phases. According to Scherrer's equation, ${ }^{23}$ the difference in the widths of the anatase and rutile peaks indicates that the anatase crystallites in the film are largest, apparently with rutile crystallites in the early stages of nucleation. The XANES from this film contradicts the XRD

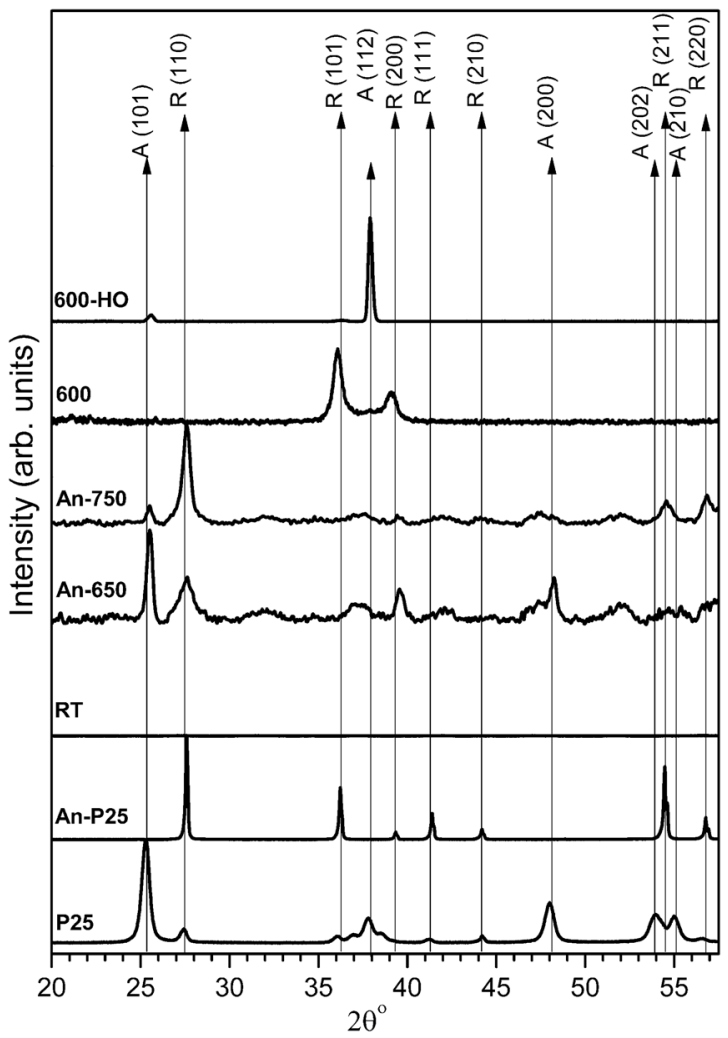

FIG. 1. X-ray diffraction from the FCVA deposited titania thin films, a $\mathrm{TiO}_{2}$ powder standard as-received (Deguss P25 with anatase:rutile:amorphous ratio of $78: 14: 8)$ and after transformation to rutile by annealing at $800^{\circ} \mathrm{C}$. Arrows marked "A" and " $\mathrm{R}$ " mark the positions of the anatase and rutile peaks, respectively. indicating that the local bonding is largely rutile. The disagreement is attributed to the presence large numbers of rutile nano-crystallites in the film and a relative lack of sensitivity to these nano-crystallites compared to the XANES. $^{24}$ As noted by Limpijumnong et al., ${ }^{24}$ XANES accurately reveals the phases present in the films (determining the photoelectronic properties) regardless of the size of the constituent crystallites. The film annealed at $750{ }^{\circ} \mathrm{C}$ exhibits a more ordered, principally rutile, microstructure. The optical bandgaps of An-650 and An-750 are both $0.1 \mathrm{eV}$ lower than the as-deposited film and the electrical resistivity increases with annealing temperature. These measurements are consistent with a reduction in defects associated with oxygen deficiency, resulting from the increased order in the annealed films.

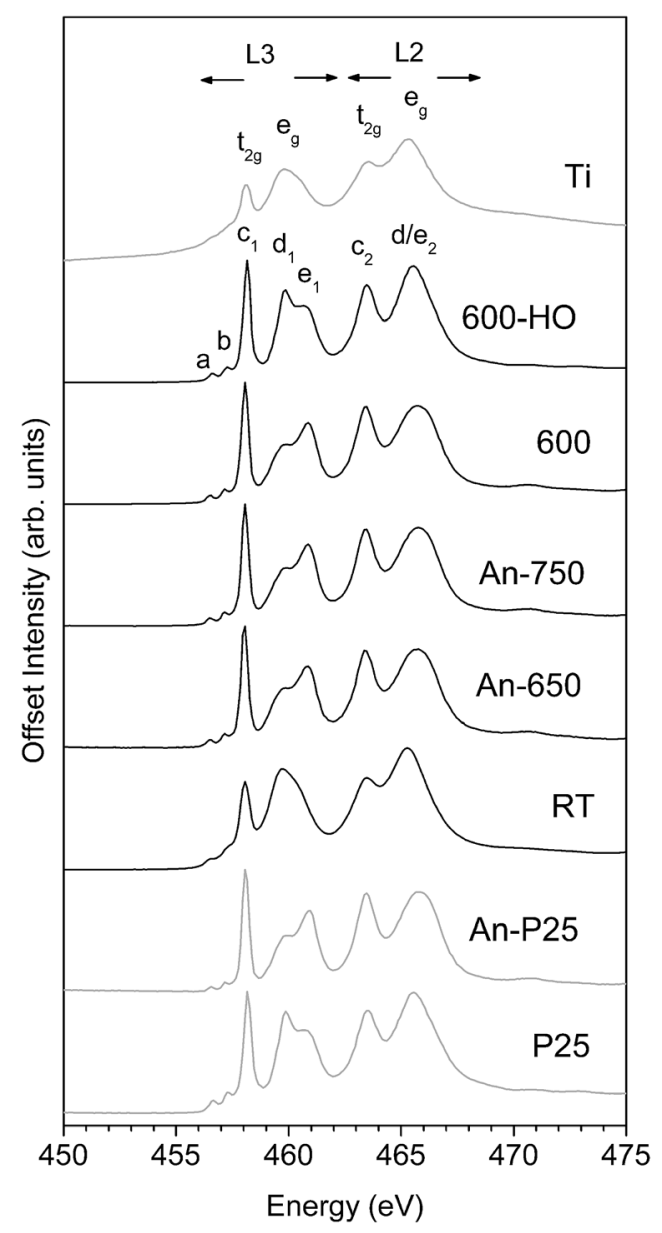

FIG. 2. XANES from the titania films (black) compared with a Ti metal foil, a powder standard as-received (Deguss P25 with anatase:rutile:amorphous ratio of 78:14:8) and after transformation to rutile by annealing at $800^{\circ} \mathrm{C}$. 


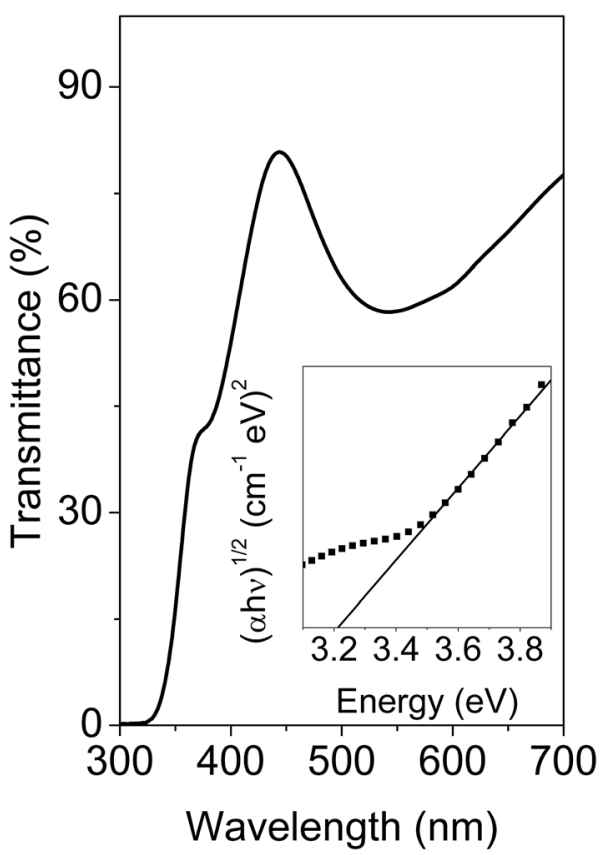

FIG. 3. UV-visible transmission from the $600-\mathrm{HO} \mathrm{TiO}_{\mathrm{x}}$ film with accompanying Tauc plot as inset.

Detectors formed on the annealed films exhibited rectifying I-V characteristics and improved sensitivity to UV light (see Table I). Fig. 4(a) shows the $I-V$ characteristics of a Pt$\mathrm{TiO}_{\mathrm{x}}$-Pt inter-digital contact structure (shown in inset) formed on An-750 measured in dark and illuminated conditions. The non-linearity of the $I-V$ characteristics results from the rectifying Schottky junctions at the $\mathrm{Pt}-\mathrm{TiO}_{\mathrm{x}}$ interfaces. The $\mathrm{UV}$ :dark current ratio measured at $+500 \mathrm{mV}$ is $>1000: 1$ (for $\lambda_{\mathrm{c}}=285 \mathrm{~nm}$ and $\left.365 \mathrm{~nm}\right)$. The photo-responsivity $(R)$ of the device at the different wavelengths is shown as an inset. Comparing $R$ at $\lambda_{\mathrm{c}}=285 \mathrm{~nm}$ with $R$ at $\lambda_{\mathrm{c}}=470 \mathrm{~nm}$, provides an ultraviolet-visible rejection ratio of $\sim 22000: 1$. Response and recovery times for this device were measured during and after $120 \mathrm{~s}$ periods of UV light exposure. The response time, defined here as the time at which the current at $500 \mathrm{mV}$ is $>90 \%$ of its maximum value during UV exposure, was $\sim 30 \mathrm{~s}$. The recovery time, defined as the time taken for the current at $500 \mathrm{mV}$ to reach $<200 \%$ of its minimum (dark) value, was $\sim 600 \mathrm{~s}$. The relatively slow response/recovery times are attributed in part to the presence of oxygen vacancies that are known to trap holes in $\mathrm{TiO}_{\mathrm{x}}$, preventing recombination with electrons after UV exposure. ${ }^{25,26}$ Molecular oxygen, bound to the defective $\mathrm{TiO}_{\mathrm{x}}$ surface is also expected to contribute to the extended response/recovery times. Adsorption of molecular oxygen on the surface of $\mathrm{TiO}_{2}$ is well characterised and central to applications in photo-catalysis. ${ }^{27}$ Whilst $\mathrm{O}_{2}$ does not adsorb on a perfect neutral $\mathrm{TiO}_{2}$ surface,$^{28}$ it does adsorb and form $\mathrm{O}-\mathrm{Ti}$ bonds when excess negative charges (photo-excited electrons and/or subsurface oxygen vacancies) are available. The $\mathrm{O}_{2}$ adsorbed on the surface of $\mathrm{TiO}_{2}$ captures photo-induced electrons as well as the free electrons located on oxygen vacancy states. This effect, coupled with the subsequent desorption of $\mathrm{O}_{2}$ and release of captured electrons, would cause prolonged response and recovery times in the $\mathrm{TiO}_{\mathrm{x}} \mathrm{UV}$ detectors.

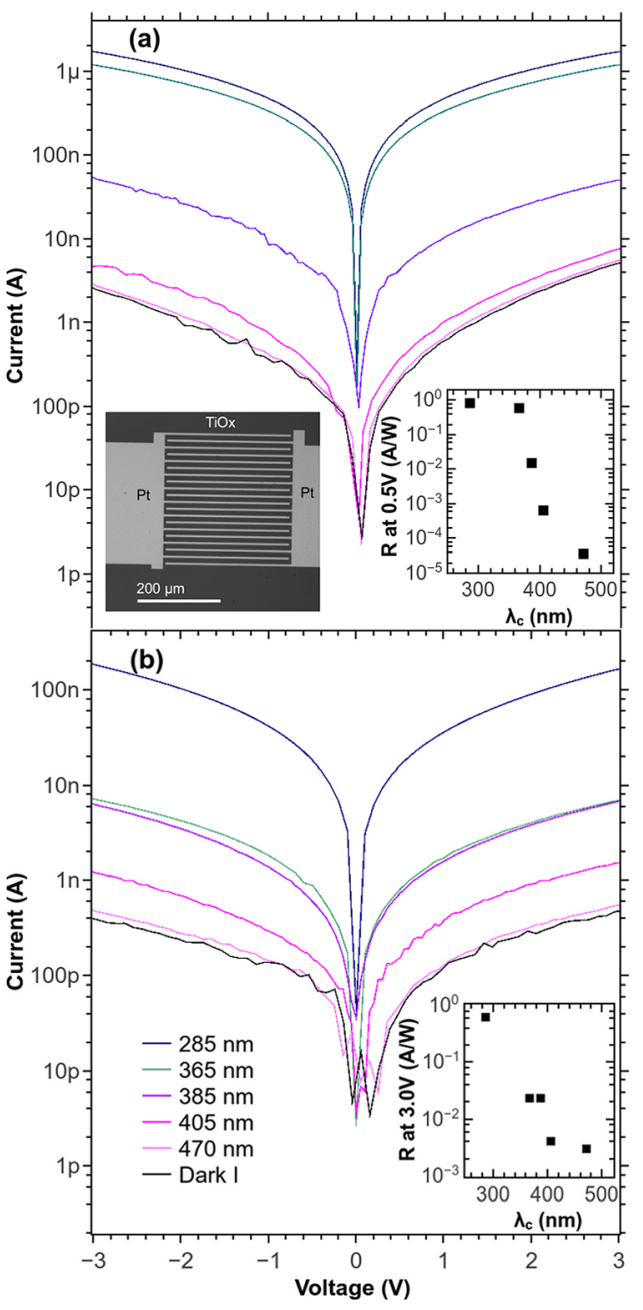

FIG. 4. Current-voltage characteristics of $\mathrm{Pt}-\mathrm{TiO}_{\mathrm{x}}-\mathrm{Pt}$ inter-digital detectors formed on (a) An-750 and (b) 600-HO titania films in dark and illuminated conditions. Insets show the contact arrangement and the photo-responsivities $(R)$ of the devices.

The effects of dynamic annealing were explored with a titania film grown at $600{ }^{\circ} \mathrm{C}$ but with otherwise identical conditions to those used for the RT film. The XRD (Fig. 1) and XANES (Fig. 2) from this "600" film show it to be dominated by the rutile phase. The XRD has prominent $\{101\}$ and $\{200\}$ rutile peaks. Whilst the preferred crystallographic orientation is different to that observed in the annealed films, the XANES shows the local bonding is similar. The $3.1 \mathrm{eV}$ optical bandgap is consistent with a largely rutile microstructure, whilst its low electrical resistance suggests the presence of a large number of active defects. This manifests itself in relatively poor UV detection (see Table I).

The aforementioned deposition was repeated but with higher oxygen pressure to reduce the effects of oxygen deficiency. This film, labelled 600-HO, produced XRD and XANES, consistent with a largely anatase ordered microstructure. Increased oxygen pressure therefore resulted in different growth to that occurring during the deposition of the 600 film. Since both deposition rate and average energy in the depositing flux are reduced with increased process pressure (due to increased collisions with the process gas), the change in growth/microstructure at higher pressure is attributed to reduced dynamic annealing. The optical bandgap of 
$600-\mathrm{HO}(3.2 \mathrm{eV})$ is consistent with its predominantly anatase microstructure. Importantly, the electrical resistivity exceeds that in all other films and the $\mathrm{Pt}-\mathrm{TiO}_{\mathrm{x}}-\mathrm{Pt}$ detector on this film is sensitive to UV light, as shown in Fig. 4(b). The inset in Fig. 4(b) shows the photo-responsivity, $R$, plotted as a function of the centre wavelength of illuminating light. Comparing $R$ at $\lambda_{\mathrm{c}}=285 \mathrm{~nm}$ with $\mathrm{R}$ at $\lambda_{\mathrm{c}}=470 \mathrm{~nm}$, provides an ultraviolet-visible rejection ratio of $\sim 200: 1$. The detectors formed on An-750 (Fig. 3(a)) and 600-HO (Fig. 3(b)) respond differently to light with $\lambda_{\mathrm{c}}=365 \mathrm{~nm}$. Due to the differing dominant phases in the films and their differing optical bandgaps, the cut-off of the detector on the An-750 film appears as expected, at a longer wavelength.

In summary, titania films energetically deposited from a filtered cathodic arc have been structurally, optically, and electronically characterised before being implemented in UV detection devices. An oxygen pressure dependent transition from anatase to rutile occurred at a growth temperature of $600^{\circ} \mathrm{C}$. All films exhibited low surface roughness and optical bandgaps between 3.1 and $3.3 \mathrm{eV}$. Higher growth and annealing temperatures resulted in higher resistivity, consistent with more efficient oxygen incorporation. $\mathrm{Pt} / \mathrm{TiO}_{\mathrm{x}} / \mathrm{Pt}$ inter-digital (back-to-back) rectifying junctions formed on the high-temperature grown and annealed films exhibited nonlinear $I-V$ characteristics and sensitivity to UV light. The most sensitive UV detector exhibited an ultraviolet-visible rejection ratio of $\sim 22000: 1$ (for $\lambda_{\mathrm{c}}=285 \mathrm{~nm}$ and $365 \mathrm{~nm}$ ).

The authors gratefully acknowledge support from the Australian Research Council (ARC), the Australian Synchrotron and the RMIT microscopy and microanalysis facility (RMMF).

${ }^{1}$ U. Diebold, Surf. Sci. Rep. 48(5-8), 53 (2003).

${ }^{2}$ R. Asahi, Y. Taga, W. Mannstadt, and A. J. Freeman, Phys. Rev. B 61(11), 7459 (2000).

${ }^{3}$ M. C. K. Sellers and E. G. Seebauer, J. Vac. Sci. Technol., A 29(6), 061503 (2011).

${ }^{4}$ J. Liu, D. Yang, F. Shi, and Y. Cai, Thin Solid Films 429(1-2), 225 (2003).
${ }^{5}$ A. D. Barros, K. F. Albertin, J. Miyoshi, I. Doi, and J. A. Diniz, Microelectron. Eng. 87(3), 443 (2010).

${ }^{6}$ X. Kong, C. Liu, W. Dong, X. Zhang, C. Tao, L. Shen, J. Zhou, Y. Fei, and S. Ruan, Appl. Phys. Lett. 94(12), 123502 (2009).

${ }^{7}$ M. Thelakkat, C. Schmitz, and H. W. Schmidt, Adv. Mater. 14(8), 577 (2002).

${ }^{8}$ N. Zhong, J. J. Cao, H. Shima, and H. Akinaga, IEEE Electron Device Lett. 33(7), 1009 (2012)

${ }^{9}$ C. H. Heo, S. B. Lee, and J. H. Boo, Thin Solid Films 475(1-2), 183 (2005).

${ }^{10}$ E. György, G. Socol, E. Axente, I. N. Mihailescu, C. Ducu, and S. Ciuca, Appl. Surf. Sci. 247(1-4), 429 (2005).

${ }^{11}$ G. A. Battiston, R. Gerbasi, A. Gregori, M. Porchia, S. Cattarin, and G. A. Rizzi, Thin Solid Films 371(1), 126 (2000).

${ }^{12}$ A. Anders, Thin Solid Films 518(15), 4087 (2010).

${ }^{13}$ A. Anders, Cathodic Arcs: From Fractal Spots to Energetic Condensation (Springer-Verlag, New York, 2008).

${ }^{14}$ S. Elzwawi, H. S. Kim, M. Lynam, E. L. H. Mayes, D. G. McCulloch, M. W. Allen, and J. G. Partridge, Appl. Phys. Lett. 101(24), 243508 (2012).

${ }^{15}$ N. Biluš Abaffy, D. G. McCulloch, and J. G. Partridge, Surf. Coat. Technol. 207(0), 529 (2012).

${ }^{16}$ M. R. Field, J. G. Partridge, E. H. Mayes, K. Latham, and D. G. McCulloch, J. Appl. Phys. 110(1), 014108 (2011).

${ }^{17}$ E. L. H. Mayes, D. G. McCulloch, and J. G. Partridge, Appl. Phys. Lett. 103(18), 182101 (2013).

${ }^{18}$ N. Biluš Abaffy, J. G. Partridge, J. du Plessis, and D. G. McCulloch, Phys. Status Solidi A 205(6), 1439 (2008).

${ }^{19}$ F. M. F. de Groot, M. Grioni, J. C. Fuggle, J. Ghijsen, G. A. Sawatzky, and H. Petersen, Phys. Rev. B 40(8), 5715 (1989).

${ }^{20}$ S. O. Kucheyev, T. van Buuren, T. F. Baumann, J. H. Satcher, Jr., T. M. Willey, R. W. Meulenberg, T. E. Felter, J. F. Poco, S. A. Gammon, and L. J. Terminello, Phys. Rev. B 69(24), 245102 (2004).

${ }^{21}$ J. Tauc, R. Grigorovici, and A. Vancu, Phys. Status Solidi B 15(2), 627 (1966).

${ }^{22}$ D. J. Won, C. H. Wang, H. K. Jang, and D. J. Choi, Appl. Phys. A 73(5), 595 (2001).

${ }^{23}$ P. Scherrer, Nachrichten von der Königl Gesellschaft der Wissenschaften zu Göttingen 1, 96 (1918).

${ }^{24}$ S. Limpijumnong, J. Jutimoosik, N. Palakawong, W. Klysubun, J. Nukeaw, M. Du, and S. Rujirawat, Appl. Phys. Lett. 99(26), 261901 (2011).

${ }^{25}$ B. J. Morgan and G. W. Watson, Phys. Rev. B 80(23), 233102 (2009).

${ }^{26}$ D. P. Colombo and R. M. Bowman, J. Phys. Chem. 99(30), 11752 (1995).

${ }^{27}$ X. Pan, M.-Q. Yang, X. Fu, N. Zhang, and Y.-J. Xu, Nanoscale 5, 3601 (2013).

${ }^{28}$ E. Lira, S. Wendt, P. Huo, J. Ø. Hansen, R. Streber, S. Porsgaard, Y. Wei, R. Bechstein, E. Lægsgaard, and F. Besenbacher, J. Am. Chem. Soc. 133, 6529 (2011). 